\title{
150-kD von Willebrand Factor Binding Protein Extracted from Human Vascular Subendothelium Is Type VI Collagen
}

\author{
Jacob H. Rand, Nayana D. Patel, Elaine Schwartz, ${ }^{*}$ Sheng-Li Zhou, * and Barry J. Potter* \\ Department of Medicine, *Divisions of Hematology and Hepatology, and ${ }^{\ddagger}$ Department of Dermatology, \\ The Mount Sinai School of Medicine, New York, New York 10029
}

\begin{abstract}
We have previously shown that von Willebrand factor (vWF), a glycoprotein which plays a critical role in the adhesion of platelets to injured blood vessels, is present within vascular subendothelium. We investigated the identity of the subendothelial binding site(s) for vWF by examining vWF binding to subendothelial constituents and solubilized a 150-kD protein with SDSurea that bound $\mathrm{vWF}$. This protein had an amino-acid composition similar to that of the type VI collagen $\alpha-1 / \alpha-2$ chains, was recognized by specific polyclonal antibodies against type VI collagen, and had a similar acidic isoelectric point. Furthermore, we found that purified type VI collagen also bound vWF. Thus, we have identified the extracted $150-\mathrm{kD}$ protein as type VI collagen. This protein may play a significant role in the binding of vWF to vascular subendothelium in vivo. (J. Clin. Invest. 1991. 88:253-259.) Key words: von Willebrand factor • collagen • subendothelium • type VI collagen • umbilical vein
\end{abstract}

\section{Introduction}

We have previously shown that von Willebrand Factor (vWF) ${ }^{1}$ is present in vascular subendothelium (1), and have also found that the deposition of vWF requires the presence of endothelial cells (2). vWF mediates the adhesion of platelets to exposed vascular subendothelium $(3,4)$ and supports subsequent thrombus formation (5). Although vWF is generally thought of as a plasma glycoprotein, platelet adhesion to subendothelium is, to a significant extent, dependent upon the pool of vWF which has been incorporated into the subendothelial matrix (6-8).

It is unclear as to how vWF is bound to the subendothelium. Although vWF is known to bind to fibrillar collagens types I and III (9-12), there are several reasons to doubt their involvement in vWF binding to subendothelium. Firstly, vascular subendothelium lacks significant quantities of these types of collagen (13-15). Also, Wagner et al. (16) concluded that the subendothelial binding site is not fibrillar collagen, because they found that collagenase digestion of tissue culture-derived subendothelial matrix did not remove vWF. Also, subendothe-

Reprint requests should be addressed to Jacob H. Rand, M.D., Hematology Division, Box 1079, Mount Sinai Medical Center, 1 Gustave L. Levy Place, New York, NY 10029.

Received for publication 20 June 1990 and in revised form 22 February 1991.

1. Abbreviation used in this paper: vWF, von Willebrand factor.

J. Clin. Invest.

(C) The American Society for Clinical Investigation, Inc. 0021-9738/91/07/253/07 \$2.00

Volume 88, July 1991, 253-259 lial matrix of cultured endothelial cells treated with $\alpha-1-\alpha-1-\mathrm{di}-$ pyridyl, an inhibitor of collagen synthesis, retained the capacity to bind vWF (16). Finally, monoclonal antibodies directed against VWF have been raised which specifically interfere with vWF-dependent platelet adhesion to subendothelial matrix but not to fibrillar collagen (17), along with antibodies which interfere with vWF-dependent platelet adhesion to the fibrillar collagens but not to subendothelium. Thus, the subendothelial binding site(s) for vWF appear(s) to be material(s) other than the fibrillar collagens.

The aim of this study was, therefore, to investigate how vWF is bound to vascular subendothelium. Studies were initiated to examine whether purified basement membrane components bind vWF. When these studies failed to detect any binding activity, we also determined whether vWF binding proteins could be identified in extracts of vascular subendothelium. One vWF binding protein was isolated and was found to be type VI collagen.

\section{Methods}

\section{A. Screening of basement membrane components}

Basement membrane components, including purified laminin, types IV and $V$ collagens and an unfractionated basement membrane extract (18), and specific polyclonal antibodies directed against laminin and types IV and V collagen were kindly provided by Dr. Hynda Kleinman and Dr. George Martin of the National Institute of Dental Research. Fibrillar collagens I and III were purchased from Sigma Chemical Co. (St. Louis, MO) and were used as positive controls to check the adequacy of the screening methods.

Protein "dot-binding" assays were performed as described (19), with the following modifications. Nitrocellulose sheets (Schleicher \& Schuell, Keene, NH) were demarcated by template into $1.0-\mathrm{cm}$ squares. Varying amounts of up to $20 \mu \mathrm{g}$ of each material, in a total volume of up to $20 \mu \mathrm{l}$, were applied to the center of each square. The sheets were then blocked with three 10-min incubations in a solution containing $0.25 \%$ BSA, $0.02 \%$ SDS, $0.1 \%$ Triton $X-100$, and $10 \mathrm{mM}$ Tris in PBS pH 7.5 at room temperature.

Binding of laminin and types IV and V collagen to the nitrocellulose sheets was demonstrated by incubating the sheets containing each protein with its specific antibody (1/500 dilution in blocking buffer) overnight at room temperature. After three washes in the blocking buffer, the sheets were incubated with a $1 / 2,000$ dilution of peroxidaseconjugated goat anti-rabbit immunoglobulins (Organon Teknika; Cappel Laboratories, Cochraneville, PA), followed by three additional 10min washes in distilled water and were then incubated with a solution containing $0.5 \mathrm{mg} / \mathrm{ml}$ chloronaphthol (Bio-Rad Laboratories, Richmond, CA), $0.01 \%$ hydrogen peroxide and $8.3 \mathrm{mM}$ sodium citrate.

The sheets were then assayed for $\mathrm{VWF}$ binding activity in the following two ways: by incubation with vWF followed by probing with antibody against vWF, and by incubation with radiolabeled vWF followed by autoradiography.

The first approach was as follows: After blocking, the sheets were incubated for up to $18 \mathrm{~h}$ in purified vWF $(20 \mu \mathrm{g} / \mathrm{ml}$ in blocking buffer $)$ at room temperature. The sheets were washed three times in the above 
blocking buffer, incubated overnight in a 1/1,000 dilution of rabbit polyclonal anti-vWF (Calbiochem-Behring Corp., San Diego, CA), washed three times in blocking buffer, and incubated for $2 \mathrm{~h}$ at room temperature with a 1/2,000 dilution of peroxidase-conjugated goat anti-rabbit immunoglobulins. After washing in distilled water, the sheets were incubated with chloronaphthol and hydrogen peroxide solution as described above.

The second approach was as performed as follows: After incubation with the above blocking buffer, the sheets were incubated overnight with $\sim 4 \mu \mathrm{Ci}$ of ${ }^{125} \mathrm{I}-\mathrm{vWF}$ (see Methods, section D) in blocking buffer. The sheets were then washed five times with blocking buffer containing $5 \%$ Tween-20, and subjected to autoradiography. Both of these methods detected the binding of vWF to types I and III collagen.

\section{B. Extraction of subendothelium}

Umbilical cords were collected immediately after delivery and the veins were flushed free of blood with isoosmotic PBS, pH 7.4, containing the following protease inhibitors to optimize protein integrity: 10 $\mathrm{mM} n$-ethyl maleimide, $5 \mathrm{mM}$ phenyl-methyl-sulfonyl-fluoride, $0.1 \mathrm{M}$ epsilon-aminocaproic acid, $50 \mathrm{mM}$ sodium ethylene-diamine-tetraacetic acid, and $5 \mathrm{mM}$ benzamidine. The veins were then mechanically deendothelialized using a modification of the Baumgartner method as previously described (1), and rinsed again with the above buffer. The lumens of the veins were incubated with $2 \%$ SDS, $8 \mathrm{M}$ urea in $0.01 \mathrm{M}$ Tris containing the above protease inhibitors ( $\mathrm{pH} \mathrm{8.0)}$ for $90 \mathrm{~min}$ at $37^{\circ} \mathrm{C}$. Typically, $\sim 5 \mathrm{ml}$ of fluid was harvested from a $15-\mathrm{cm}$ length of umbilical vein, yielding a protein concentration $(20)$ of $2-5 \mathrm{mg} / \mathrm{ml}$. Subsequent to our initial identification of a $150-\mathrm{kD} \mathrm{vWF}$-binding protein in these extracts as a component of type VI collagen (see below), the procedure was improved by the addition of $0.02 \mathrm{M}$ dithioerythritol (DTE) to the incubating solution. The extracts were initially screened for vWF binding activity by nitrocellulose dot-binding utilizing radioiodinated VWF as the probe as described above in section A. To assess the effects of the extraction process upon the internal elastic lamina, $0.5-1-\mathrm{cm}$ cross-slices of umbilical vein were obtained before and after extraction, frozen in methylbutane containing dry ice, and embedded in O.C.T. (Miles Laboratories, Inc., Napierville, IL). Frozen cross-sections, measuring 2-4 mm were cut and mounted on glass slides, after which they were stained with Jenner-Giemsa and viewed.

\section{Polyacrylamide gel electrophoresis and radioligand binding studies}

The proteins in the extracts were resolved by electrophoresis through discontinuous PAGE $(21,22)$. The gels consisted of $4 \%$ (wt/vol) stacking gels over 5-15\% linear gradient gel. Prestained molecular weight markers (BRL Laboratories, Gaithersburg, MD) ranging between 14,000 and 200,000 were used. After electrophoresis, the gels were equilibrated in $20 \mathrm{mM}$ sodium phosphate buffer, $\mathrm{pH} 8.0$, and were electrophoretically transferred at $2 \mathrm{~A}$ for $2 \mathrm{~h}$ at $4^{\circ} \mathrm{C}$ onto nitrocellulose sheets using an E-C electroblot chamber with an E-C 420 power supply (E-C Apparatus, St. Petersburg, FL) $(23,24)$.

The nitrocellulose sheets were incubated with three changes of the same blocking buffer described above for the dot-blotted proteins for a total of $30 \mathrm{~min}$. The blots were then incubated overnight with $\sim 4 \mu \mathrm{Ci}$ of ${ }^{125}$ I-vWF in the blocking buffer with or without a 20 -fold excess of unlabeled vWF. The sheets were then washed with five changes of blocking buffer containing $0.5 \%$ Tween-20, dried, and autoradiographed using Kodak XAR-2 film in Kodak cassettes with Lanex enhancement screens and kept at $-80^{\circ} \mathrm{C}$ until they were developed.

\section{Radiolabeling of $v W F$}

$\mathrm{vWF}$ was prepared from fresh frozen plasma and cryoprecipitate as described (1), and was labeled with ${ }^{125}$ I by Iodogen (Pierce Chemical Co., Inc., Rockford, IL) as described (25). Labeled vWF was separated from free ${ }^{125}$ I by chromatography through PD-10 columns containing Sephadex G-25 (Pharmacia Fine Chemicals, Piscataway, NJ) and the protein-associated peak was collected. Typically, the specific activity of the preparation was $\sim 0.2 \mu \mathrm{Ci} / \mu \mathrm{g}$ of protein. Radioactivity was mea- sured with a model 1197 automatic gamma counter (Tracor Analytical, Chicago, IL).

\section{$E$. Isolation of $v W F$ binding protein}

Subendothelial extracts were electrophoresed into 5-15\% gradient polyacrylamide gels that were modified by having a long central trough to increase the specimen load. After electrophoresis, the $150-\mathrm{kD}$ band was removed. The strips of gel containing the band were chopped and electroeluted (26) at $3 \mathrm{~W}$ constant power at $0^{\circ} \mathrm{C}$ for $2 \mathrm{~h}$ using an ISCO model 1750 sample concentrator apparatus. The protein was concentrated by centrifugation through Centricon- 10 microconcentrators (Amicon) and the protein concentration was then determined by the method of Bradford (20). The extent of purity of the eluates was evaluated by silver staining (27) of electroeluted bands following reelectrophoresis on SDS-PAGE.

\section{$F$. Characterization of the $150-k D$ protein}

$v W F$ binding activity. Varying quantities of protein, between 0.75 and $6 \mu \mathrm{g}$, were dot-blotted onto nitrocellulose sheets, as described above in section $\mathrm{A}$, washed with blocking buffer, and incubated with $\sim 4 \mu \mathrm{Ci}$ of ${ }^{125} \mathrm{I}$-vWF in blocking buffer overnight. The experiments were performed in pairs, one of which included a 20-fold excess of unlabeled vWF. The blots were washed with $0.5 \%$ Tween-20 in the blocking buffer and autoradiography was performed as described above. The pairs of autoradiograms were exposed under identical conditions and were scanned with an LKB Ultroscan XL laser densitometer.

Isoelectric focusing. Isoelectric focusing was performed utilizing LKB Ampholine PAG plates with ampholytes having a pH range of 3.5-9.5 following the procedure recommended in the supplier's manual. Samples were applied in various positions in different lanes to avoid potential artifacts caused by the sample application sites. The gels were then fixed in a solution of $30 \%$ methanol $10 \%$ TCA $3.5 \%$ 5 -sulfosalicylic acid in water for $1 \mathrm{~h}$, followed by $30 \%$ methanol/12\% TCA for $2 \mathrm{~h}$, followed by two separate incubations of $15 \mathrm{~min}$ each in $10 \%$ ethanol/5\% acetic acid. The gels were then silver stained as described (27).

Radioimmunoligand Western blot studies. For radioimmunoligand blots, the nitrocellulose sheets were blocked with $2 \%$ nonfat dry milk in PBS, pH 7.5. They were incubated overnight with specific rabbit antisera against collagens types I, III, and VI. The antitypes I and III were kindly provided by Dr. Hynda Kleinman and Dr. George Martin of the National Institutes of Dental Research, and the antitype VI was provided by Dr. Rupert Timpl of the Max Planck Institute. The blots were then washed with three changes of blocking buffer at 10 min each, followed by three changes of PBS, and then were incubated with 2.5 $\mu \mathrm{Ci}$ of ${ }^{125}$ I-protein A (Amersham Corp., Arlington Heights, IL) for $1 \mathrm{~h}$ in PBS without the nonfat dry milk, following which they were again washed in PBS and autoradiographed as described above.

Amino acid analysis. Lyophilized specimens were hydrolyzed for $24 \mathrm{~h}$ in constant boiling $\mathrm{HCl}$ at $107^{\circ}$ under vacuum. Amino acid residues were derivatized with 9-fluorenylmethylchloroformate and were

\section{Table I. Binding of vWF to Extracellular Matrix Constituents}

\begin{tabular}{|c|c|}
\hline Basement membrane extract* & - \\
\hline Subendothelial extract ${ }^{\ddagger}$ & + \\
\hline Laminin* & - \\
\hline Type IV collagen* & - \\
\hline Type V collagen* & - \\
\hline
\end{tabular}

* As described in Methods, these studies were negative by dot-binding assays nitrocellulose assays done separately with both radiolabeled vWF and with unlabeled vWF which was probed with anti-vWF antibodies. ${ }^{*}$ Probed by radiolabeled vWF alone, because it contains endogenous vWF which would be detected by anti-vWF antibodies. 
then resolved by reverse-phase HPLC (28) using a $250 \times 4.6 \mathrm{~mm}$ Spherisorb ODS-2 column in a Kratos chromatographic system (Applied Biosystems, Foster City, CA). The separations were carried out at a flow rate of $1-1 / \mathrm{min}$ by gradient elution, using $60 \%$ acetic acid $(0.37 \%, \mathrm{pH} 4.2), 15 \% \mathrm{H}_{2} \mathrm{O}, 25 \%$ acetonitrile, and for the first $15 \mathrm{~min}$, then progressing to $8 \%$ acetic acid, $7 \% \mathrm{H}_{2} \mathrm{O}$, and $65 \%$ acetonitrile over the following $60 \mathrm{~min}$.

\section{G. $v W F$ binding activity of purified type VI collagen}

Human type VI collagen was kindly provided by Dr. Rupert Timpl (29). The lyophilized protein was dissolved in $0.2 \mathrm{M}$ acetic acid to yield varying quantities of protein, ranging between 1.25 and $10 \mu \mathrm{g}$ which were then applied onto strips of nitrocellulose paper to form dot-blots. After this, the strips were treated as described above for the vWF binding protein.

\section{Results}

Our screening studies of all the initial candidate materials, including laminin, types IV and V collagen, and an unfractionated basement membrane extract failed to demonstrate any binding to vWF using both screening methods (Table I). Because of these negative studies, we proceeded to investigate extracts of blood vessel subendothelium. When assays of the
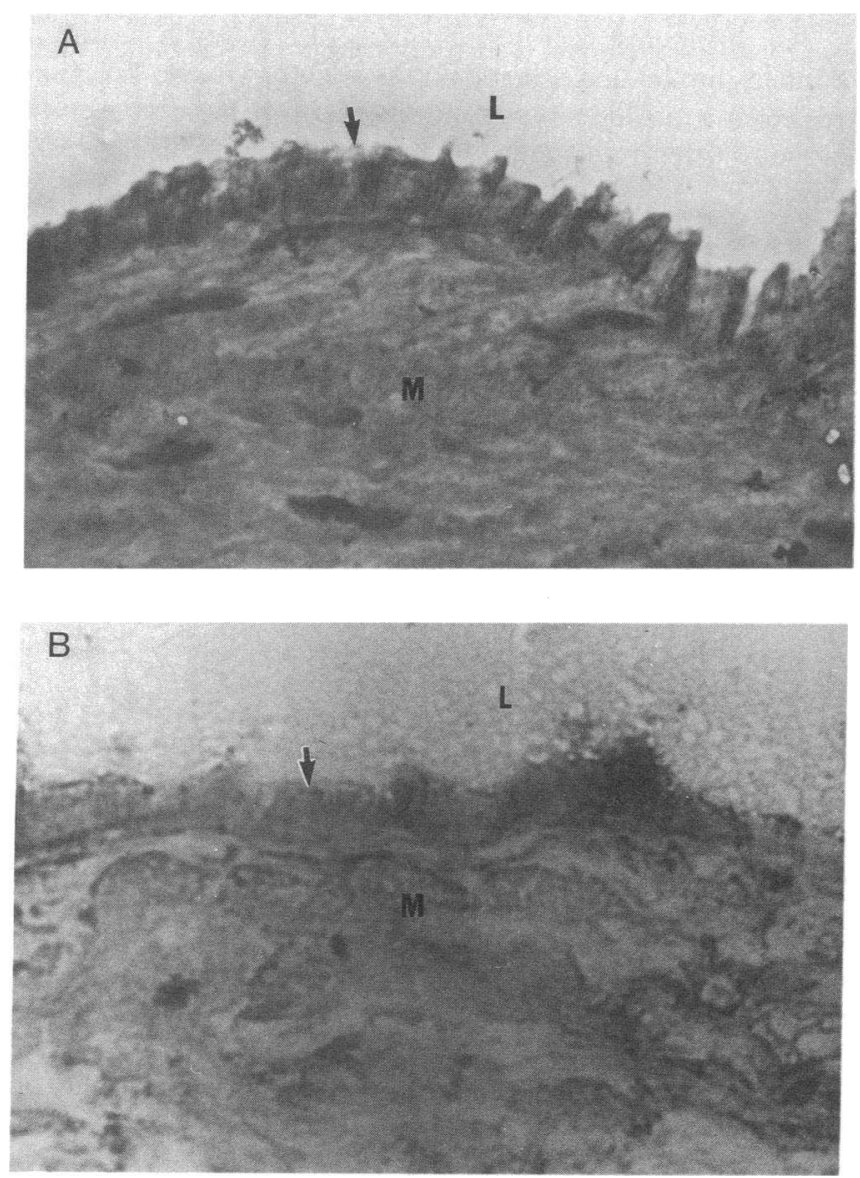

Figure 1. Histology of the umbilical vein pre- and postextraction of subendothelium. (a) Preextraction deendothelialized umbilical vein showing internal elastic lamina (arrow), above the media $(M)$, facing lumen $(L)$. $(b)$ Deendothelialized umbilical vein postextraction of subendothelium. The internal elastic lamina (arrow) is noted to be intact (original magnifications, 400).

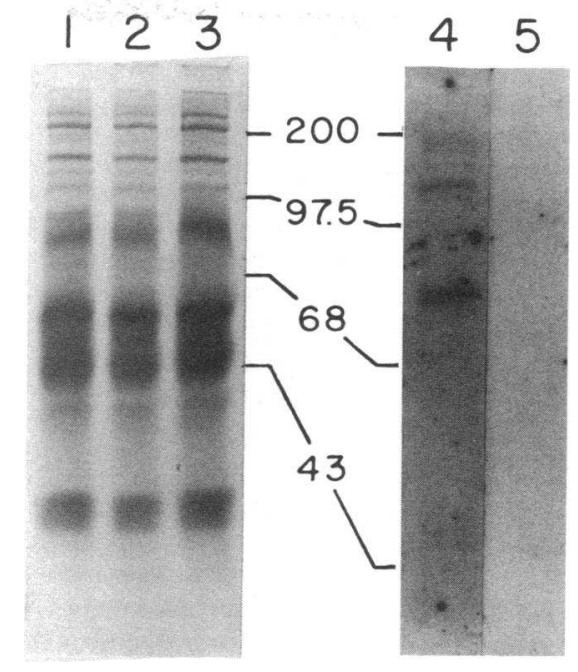

Figure 2. Binding of ${ }^{125} \mathrm{I}$-vWF to electroblotted subendothelial extract. (Lanes 1-3) Coomassie blue-stained unboiled, boiled, and reduced and boiled SDS-urea extracts of subendothelium, respectively. After electroblotting onto nitrocellulose paper, the unboiled extract binds ${ }^{125} \mathrm{I}-\mathrm{vWF}$ at a position which are consistent with a mass of $150 \mathrm{kD}$, with two additional bands observed at positions consistent with masses of $\sim 200$ and $80 \mathrm{kD}$ (lane 4). The binding of ${ }^{125} \mathrm{I}-\mathrm{vWF}$ is blocked in the presence of a 20 -fold excess of unlabeled vWF (lane 5).

subendothelial extracts demonstrated vWF binding activity (Table I), we undertook the subsequent experiments to identify which components of the subendothelium are responsible for the binding activity.

The histology of the deendothelialized umbilical vein was observed before and after extraction of subendothelium (Fig. 1). The extraction procedure did not result in disruption of the internal elastic lamina. Protein bands were resolved from the extract by gradient polyacrylamide gel electrophoresis (Fig. 1). When the proteins were electroblotted onto nitrocellulose, incubated with ${ }^{125} \mathrm{I}-\mathrm{vWF}$ and autoradiographed, three major protein bands with molecular weights of $200,000,150,000$, and 80,000 were observed. The appearance of the bands was blocked by coincubation of the ${ }^{125} \mathrm{I}-\mathrm{vWF}$ with an excess of unlabeled vWF (Fig. 2).

By means of electroelution, protein showing single bands at the $150 \mathrm{kD}$ position, as assessed by silver staining of polyacrylamide gels, was obtained (Fig. 3). The $150-\mathrm{kD}$ protein retained the capacity to bind vWF specifically (Fig. 4, Table II). Binding could be blocked by a 20 -fold excess of unlabeled vWF. The protein had an isoelectric point of $6.0 \pm 0.2$ (Fig. 5).

Western blot studies utilizing specific antisera against collagens showed reactivity between the $150-\mathrm{kD}$ protein and antitype VI collagen antibodies, but not with antibodies against types I or III collagens (Fig. 6). Subsequent Western blot studies utilizing the whole vessel extract, also demonstrated identification of the $150-\mathrm{kD}$ band by the antitype VI collagen antibodies, along with higher molecular weight bands (Fig. 7).

Amino acid analysis (Table III) showed the $150-\mathrm{kD}$ material to be a protein containing significant quantities of proline (71 residues/1,000 residues) and hydroxyproline (10 residues/ 1,000 residues).

Purified type VI collagen, which had been derived by standard methods, and was dot-blotted onto nitrocellulose sheets 


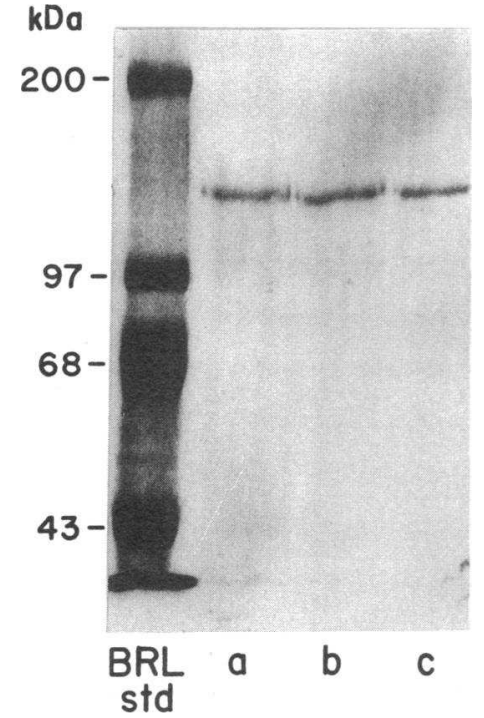

Figure 3. Electroeluted 150-kD protein. Silverstained $5-10 \%$ gradient SDS-PAGE showing the protein obtained after slicing and electroelution of the $150-\mathrm{kD}$ band from preparative polyacrylamide gels. First lane shows the high molecular weight standards. (Lanes $A-C$ ) Three different electroeluted preparations. All three preparations are homogeneous for the $150-\mathrm{kD}$ protein.

also bound ${ }^{125}$ I-vWF (Fig. 8 and Table IV). This binding was also inhibited by a 20 -fold excess of unlabeled vWF.

In summary, after we were unable to demonstrate any vWF binding activity in purified basement membrane and unfractionated basement membrane preparations, we proceeded to studies with extracts of human umbilical vein subendothelium. Using an SDS-urea extract of subendothelium, we identified and characterized a $150-\mathrm{kD} v W F-b i n d i n g$ protein which is recognized by antibodies against type VI collagen, has a pI of $\sim 6.0$, and has the amino acid composition of a collagenlike protein. Also, we found that purified type VI collagen binds vWF specifically.

\section{Discussion}

We have identified a $150-\mathrm{kD}$ vWF-binding protein which shares characteristics of type VI collagen, and have furthermore found that purified type VI collagen binds to vWF. The $150-\mathrm{kD}$ protein that we have isolated binds vWF and is recognized by

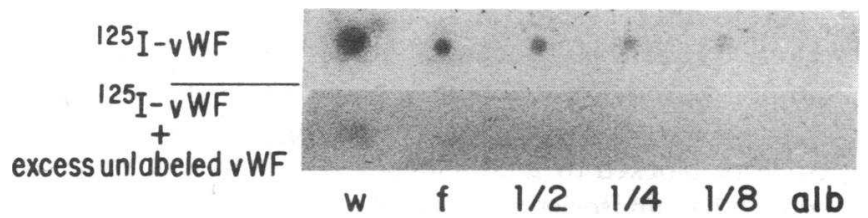

Figure 4. Binding of ${ }^{125} \mathrm{I}-\mathrm{vWF}$ to electroeluted $150-\mathrm{kD}$ protein. These are autoradiograms of nitrocellulose strips onto which the electroeluted $150-\mathrm{kD}$ protein was dot-blotted and then incubated with ${ }^{125} \mathrm{I}$ vWF. The upper strip was incubated with $4 \mu \mathrm{Ci}$ of ${ }^{125} \mathrm{I}-\mathrm{vWF}$, and the lower strip was incubated with the same quantity of radioiodinated vWF in the presence of a 20 -fold excess of unlabeled vWF. The first dot is the whole unfractionated whole extract before electroelution $(W)$, followed by the "full-strength" $150-\mathrm{kD}$ protein with $6 \mu \mathrm{g} / \mathrm{dot}$, followed by $1 / 2,1 / 4$, and $1 / 8$ serial dilutions containing $3,1.5$, and 0.75 $\mu \mathrm{g}$ per dot, respectively. The last dot contains $1.6 \mu \mathrm{g}$ BSA $(\mathrm{alb})$. There is correlation between the quantity of $150-\mathrm{kD}$ protein blotted and the amount of vWF which is bound. Densitometric analysis is shown in Table III. Binding of ${ }^{125} \mathrm{I}-\mathrm{vWF}$ to the $150-\mathrm{kD}$ protein is blocked by an excess of unlabeled vWF.
Table II. Densitometric Analysis of Binding of ${ }^{125} \mathrm{vWF}$ to Electroeluted 150-kD Protein

\begin{tabular}{cc}
\hline Quantity of $150-\mathrm{kD}$ protein & Binding of ${ }^{125} \mathrm{vWF}$ \\
\hline$\mu g$ & arbitrary densitometric units \\
6.0 & 122.0 \\
3.0 & 64.3 \\
1.5 & 41.7 \\
0.75 & 36.5 \\
\hline
\end{tabular}

Densitometric analysis of autoradiograms of nitrocellulose dot blots, to which varying quantities of the isolated $150 \mathrm{kD}$ were applied, followed by incubation with ${ }^{125} \mathrm{I}-\mathrm{vWF}$. The arbitrary densitometric units represent the calculated area under each curve.

antibodies against type VI collagen, but not by antibodies against types I and III collagen. Also, its amino acid composition demonstrates a hydroxyproline-containing collagenlike protein which is similar to the compositions which have thus far been reported for type VI collagen (30-33). Also, unlike the fibrillar collagens which have basic pI's, the $150-\mathrm{kD}$ vWF-binding protein had a pI of $\sim 6.0$, similar to that previously reported for the $150-\mathrm{kD}$ subunit of type VI collagen (34).

It is of interest that whereas type VI collagen has, with a different purification scheme and in different tissues been extracted in a disulfide bonded form (35), our initial extraction method, without reduction, identified the presence of free chains. There was, however, increased yield in the amount of $150-\mathrm{kD}$ protein obtained after incubation with $0.02 \mathrm{M}$ DTE. The presence of free chains has been previously described in porcine fibroblasts (34), human WI-38 fibroblasts (36), and in cutis laxa fibroblasts (37) but has not been observed in vascular subendothelium.

With respect to previous work on the vascular binding of vWF, our finding of type VI collagen in the subendothelium is consistent with the studies of Fauvel et al. who had concluded that microfibrils constitute the blood vessel binding site for vWF (38), because it is now known that type VI collagen is a major component of the microfibrils. They showed that microfibrils extracted from bovine aorta using $6 \mathrm{M}$ guanidine $\mathrm{HCl}$

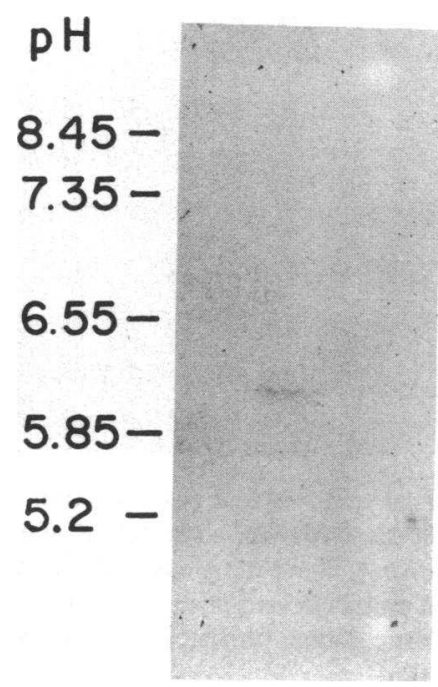

Figure 5. Isoelectric focusing of the $150-\mathrm{kD}$ protein and subsequent silver staining reveals the protein to have a pI of $6.0 \pm 0.2$. 


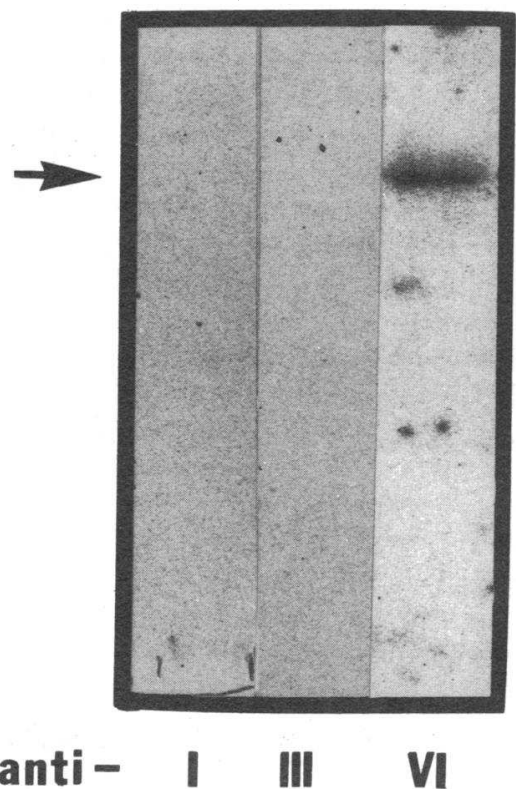

Figure 6. Recognition of the electroeluted 150$\mathrm{kD}$ protein by antitype VI collagen antibodies. These are autoradiograms of Western blots of the electroeluted 150$\mathrm{kD}$ protein which were incubated with specific antisera against collagens types I, III, and VI, followed by incubation with ${ }^{125}$ I-protein A, as described in Methods. The antitype VI collagen antibodies recognize the $150-\mathrm{kD}$ protein, whereas the antitypes I and III collagen antibodies do not.

cancel platelet aggregation mediated by vWF, indicating that the vWF became bound to the microfibrils. It should, however, be noted that Perret et al. doubted the composition of the material extracted by Fauvel's group (39).

Our work also may explain the results of Wagner et al. (16) who, in tissue culture studies, found evidence that the extracellular matrix binding site for vWF is resistant to digestion by bacterial collagenase. Native type VI collagen has that property $(29,40)$, whereas fibrillar collagens do not.

The histology of the umbilical veins postextraction of subendothelium showed an intact internal elastic lamina indicat-

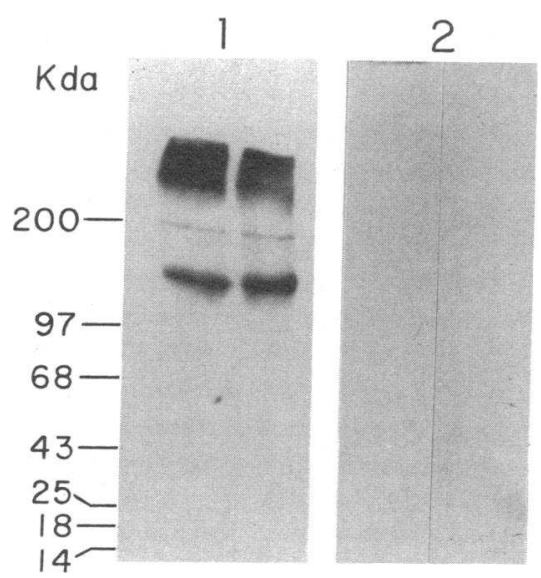

Figure 7. Reactivity of whole subendothelial extract with antitype VI collagen antibodies. These are autoradiograms of Western blots of the whole subendothelial extract which show reactivity of antitype VI collagen antibodies with the $150-\mathrm{kD}$ protein along with additional bands at higher molecular weights. The left blot had been incubated with rabbit antitype VI collagen, followed by ${ }^{125} \mathrm{I}$-protein $\mathrm{A}$, as described in Methods. The right blot was similarly treated except for having been incubated with normal rabbit serum in place of the antitype VI antibody. The major bands recognized by the antitype VI antibody are at the $150-\mathrm{kD}$ and $240-260-\mathrm{kD}$ positions, along with a fainter band at the $200-\mathrm{kD}$ position.
Table III. Amino Acid Compositions (Residues per 1,000 Residues) of 150-kD vWF-binding Protein Isolated from Subendothelium and Type VI Collagen Alpha Chains

\begin{tabular}{lcc}
\hline Amino acid residue & Subendothelial $150-k D$ protein & Fibroblasts (reference 31) \\
\hline Hydroxyproline & 10 & 14 \\
Proline & 71 & 69 \\
Aspartic acid & 56 & 103 \\
Serine & 79 & 71 \\
Glutamic acid & 166 & 116 \\
Threonine & 48 & 70 \\
Glycine & 156 & 134 \\
Arginine & 73 & 24 \\
Alanine & 94 & 59 \\
Tyrosine & nd & 26 \\
Valine & 55 & 60 \\
Phenylalanine & 10 & 32 \\
Isoleucine & 26 & 44 \\
Leucine & 73 & 79 \\
Hydroxylysine & 9 & 9 \\
Lysine & 74 & 34 \\
Histidine & nd & 16 \\
Methionine & nd & 11 \\
& & \\
\hline
\end{tabular}

ing that the material derived from our extraction procedure was most likely subendothelial in nature. However, we cannot totally exclude the possibility that the extraction procedure resulted in removal of protein from deeper portions of the blood vessel. We should also point out that our work utilized umbilical veins, and that these findings cannot yet be generalized to other blood vessels.

Type VI collagen is an important component of microfibrillar structures in the extracellular matrix (for review see reference 41). The molecular weights of its $\alpha-1$ and $\alpha-2$ chains are in the range of 140,000-160,000 (33). This form of collagen was initially isolated from blood vessel intima (42) and is currently recognized to be present in a variety of different tissues. It is unique among the collagens in that somewhat less than half of its mass is triple-helical, the larger portion of the protein being globular. By rotary shadow imaging, type VI collagen has been

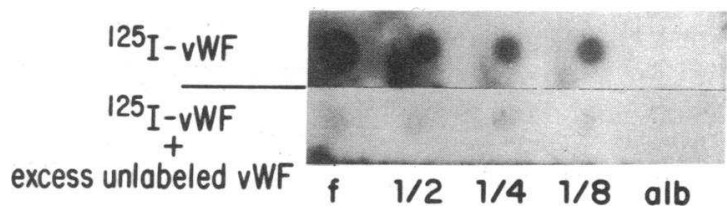

Figure 8. Binding of ${ }^{125} \mathrm{I}-\mathrm{vWF}$ to purified type VI collagen. These are autoradiograms of nitrocellulose dot blots of purified type VI collagen 1ncubated with ${ }^{125} \mathrm{I}-\mathrm{vWF}$ performed in the same manner as the experiment with the electroeluted 150-kD protein shown in Fig. 3. 10 $\mu \mathrm{g}$ of protein were applied to square $(f)$; the $1 / 2,1 / 4$, and $1 / 8$ squares are serial dilutions containing 5.0, 2.5, and $1.25 \mu \mathrm{m}$ of type VI collagen, respectively. The last dot (alb) has $1.6 \mu \mathrm{g}$ of BSA. The top strip was incubated with $4 \mu \mathrm{Ci}$ of ${ }^{125} \mathrm{I}-\mathrm{vWF}$; the bottom strip was incubated with the same amount of labeled vWF together with a 20-fold excess of unlabeled protein. There is a correlation between the amount of type VI collagen applied and the amount of vWF bound (Table III). Binding of ${ }^{125} \mathrm{I}-\mathrm{vWF}$ is inhibited by the presence of excess unlabeled vWF. 
Table IV. Densitometric Analysis of Binding of ${ }^{125} I-v W F$ to Type VI Collagen

\begin{tabular}{cc}
$\begin{array}{c}\text { Quantity of type VI } \\
\text { collagen protein }\end{array}$ & $\begin{array}{c}\text { Binding of } \\
\text { 125 I-vWF }\end{array}$ \\
\hline$\mu g$ & arbitrary densitometric units \\
10.0 & 175.7 \\
5.0 & 86.1 \\
2.5 & 43.2 \\
1.25 & 31.0
\end{tabular}

Densitometric analysis of autoradiograms of nitrocellulose dot blots, to which varying quantities of the purified type VI collagen were applied, followed by incubation with ${ }^{125} \mathrm{I}-\mathrm{vWF}$. The arbitrary densitometric units represent the calculated area under each curve.

observed to have a dumbell-like structure in which the central fibrillar domain is attached at each end to large globular domains $(29,43)$.

Because the domains on vWF which are involved in binding to types I and III collagen have been identified (44-48), and the structure of type VI collagen is known, it would be interesting to learn whether there is specificity in the interaction of any of the vWF domains with the various domains of type VI collagen. Specifically, are the portions of vWF which bind to type VI collagen the same as those responsible for binding to fibrillar collagens? And, is the fibrillar portion of the type VI molecule the region which is recognized by vWF, or do the globular portions of the molecule play a role in this binding? Interestingly, in preliminary studies, we have been unable to inhibit the binding of vWF to type VI collagen with specific antitype VI antibodies. Because these antibodies are extensively cross-absorbed with fibrillar collagens to remove cross-reactive species, it is intriguing to speculate that the binding site(s) for vWF is present on shared domain(s).

It has recently been reported that the amino acid sequence of the globular domain of type VI collagen shows striking homology to the collagen binding motifs of VWF (49-51), and also has a region which bears homology to platelet glycoprotein Ib (52). Thus, a portion of the type VI collagen protein also shares vWF's collagen binding structure, and a portion shares homology to a glycoprotein which serves as the major platelet binding site for VWF. However, the functional significance of these homologies and the questions of whether vWF itself binds to type VI collagen via vWF's previously described binding domains for fibrillar collagens, or via a different mechanism, or a combination of mechanisms, still remain to be determined.

We have not yet identified the $80-\mathrm{kD}$ band which binds vWF and suspect that this may be a partially proteolyzed chain of type VI collagen.

In conclusion, this study is the first identification of a vWFbinding protein in subendothelium. These studies implicate type VI collagen in the process of VWF binding to subendothelium and, therefore, to the process of platelet adhesion. Studies are in progress in our laboratory to further characterize the binding of vWF to type VI collagen.

\section{Acknowledgments}

We wish to thank Dr. Rupert Timpl and Dr. Yale Nemerson for their encouragement and helpful criticisms of this study, Ms. Mayra Lema and Ms. Sadie Chu for their technical assistance, and Ms. Diana Vasquez and Ms. Mary Barrett for secretarial assistance. 32200

This work was supported by National Institutes of Health No. HL

\section{References}

1. Rand, J. H., I. I. Sussman, R. E. Gordon, S. V. Chu, and V. Solomon. 1980. Localization of factor VIII-related antigen in human vascular subendothelium. Blood. 55:752-756.

2. Sussman, I. I., and J. H. Rand. 1982. Vascular deposition of von Willebrand's factor requires endothelial cells. J. Lab. Clin. Med. 100:526-532.

3. Tschopp, T. B., H. J. Weiss, and H. R. Baumgartner. 1974. Decreased adhesion of platelets to subendothelium in von Willebrand's disease. J. Lab. Clin. Med. 83:296-300.

4. Badimon, L., J. J. Badimon, J. Rand, V. T. Turitto, and V. Fuster. 1987. Platelet deposition on von Willebrand factor-deficient vessels. Extracorporeal perfusion studies in swine with von Willebrand's disease using native and heparinized blood. J. Lab. Clin. Med. 110:634-647.

5. Turitto, V. T., H. J. Weiss, and H. R. Baumgartner. 1984. Platelet interaction with rabbit subendothelium in von Willebrand's disease: altered thrombus formation distinct from defective platelet adhesion. J. Clin. Invest. 74:17301741.

6. Sakariassen, K. S., P. A. Bolhuis, and J. J. Sixma. 1979. Human blood platelet adhesion to artery subendothelium is mediated by factor VIII-von Willebrand factor bound to the subendothelium. Nature (Lond.). 279:636-638.

7. Stel, H. V., K. S. Sakariassen, and P. G. De Groot. 1985. von Willebrand factor in the vessel wall mediates platelet adherence. Blood. 65:85-90.

8. Turitto, V. T., H. J. Weiss, T. S. Zimmerman, and I. I. Sussman. 1985. Factor VIII/von Willebrand factor in subendothelium mediates platelet adhesion. Blood. 65:823-831.

9. Nyman, D. 1977. Interaction of collagen with the factor VIII antigen-activity von Willebrand factor complex. Thromb. Res. 11:433-438.

10. Santoro, S. A., and J. F. Cowan. 1982. Absorption of von Willebrand factor/factor VIII by fibrillar collagen. Implications concerning the adhesion of platelets to collagen. Coll. Relat. Res. 2:31-34.

11. Bockenstedt, P., J. McDonagh, and R. I. Handin. 1986. Binding and covalent cross-linking of purified von Willebrand factor to native monomeric collagen. J. Clin. Invest. 78:551-556.

12. Roth, G. J., K. Titani, L. W. Hoyer, and M. J. Hickey. 1986. Localization of binding sites within human von Willebrand factor for monomeric type III collagen. Biochemistry. 25:8357-8361.

13. Madri, J. A., B. Dreyer, F. A. Pitlick, and H. Furthmayr. 1981. The collagenous components of the subendothelium. Correlation of structure and function. Lab. Invest. 43:303-315.

14. Sheklonin, B. V., S. P. Domogatsky, S. P. Muzykantov, and G. L. Idelson. 1985. Distribution of type I, III, IV and V collagen in normal and atherosclerotic human arterial wall: immunomorphological characteristics. Coll. Relat. Res. 5:355-368.

15. Voss, B., and J. Rauterberg. 1986. Localization of collagen types I, III, IV, and $\mathrm{V}$, fibronectin and laminin in human arteries by indirect immunofluorescence method. Pathol. Res. Pract. 181:568-575.

16. Wagner, D. D., M. Urban-Pickering, and V. J. Marder. 1984. von Willebrand protein binds to extracellular matrix independently of collagen. Proc. Natl. Acad. Sci. USA. 81:471-475.

17. de Groot, P. G., M. Ottenhof-Rovers, J. A. van Mourik, and J. J. Sixma 1988. Evidence that the primary binding site of von Willebrand factor that mediates platelet adhesion to subendothelium is not collagen. J. Clin. Invest. 82:6573.

18. Kleinman, H. L., M. L. McGarvey, and J. R. Hasse. 1983. Formation of supramolecular complex is involved in the reconstitution of basement membrane components. Biochemistry. 22:4969-4974.

19. Hatamochi, A., M. Aumailley, C. Mauch, M.-L. Chu, R. Timpl, and T. Krieg. 1989. Regulation of collagen VI expression in fibroblasts. Effects of cell density, cell matrix interactions and chemical transformation. J. Biol. Chem. 264:3494-3499.

20. Bradford, M. M. 1976. A rapid sensitive method for the quantitation of microgram quantities of protein utilizing the principles of protein-dye binding. Anal. Biochem. 72:248-254.

21. Laemmli, U. K. 1970. Cleavage of structural proteins during the assembly of the head of the bacteriophage T4. Nature (Lond.). 227:680-685.

22. Neville, D. M. 1971. Molecular weight determination of protein-dodecyl sulfate complexes by gel electrophoresis in a discontinuous buffer system. J. Biol. Chem. 246:6328-6334.

23. Towbin, H., T. Staehlin, and R. E. Gordon. 1981. Electrophoretic transfer of proteins from polyacrylamide gels to nitrocellulose sheets: procedure and some applications. Proc. Natl. Acad. Sci. USA. 76:4350-4354. 
24. Burnette, W. N. 1981. Western blotting: electrophoretic transfer of proteins from sodium dodecyl sulfate-polyacrylamide gels to unmodified nitrocellulose and radiographic detection with antibody and radioiodinated protein. Anal. Biochem. 112:195-203.

25. Salacinski, P. R. P., C. McLean, J. E. C. Sykes, V. V. Clement-Jones, and P. J. Lowry. 1981. Iodination of proteins, glycoprotein, and peptides using a solid-phase oxidizing agent 1,3,4,6-tetrachloro-3-alpha-6-alpha-dephenyl glycoluril (lodogen). Anal. Biochem. 117:136-146.

26. Liederman, I. Z., M. L. Greenberg, B. R. Adelsberg, and F. P. Siegal. 1987 A glycoprotein inhibitor of in vitro granulopoeisis associated with AIDS. Blood. 70:1267-1272.

27. Merril, C. R., R. C. Switzer, and M. L. van Keuren. 1979. Trace polypeptides in cellular extracts and human body fluids detected by two-dimensional electrophoresis and a highly sensitive silver stain. Proc. Natl. Acad. Sci. USA 76:4335-4339.

28. Einarsson, S, B. Josefsson, and S. Lagerkvist. 1983. Determination of amino acids with 9-fluorenylmethyl chloroformate and reversed-phase high-performance liquid chromatography. J. Chromatogr. 282:609-618.

29. von der Mark, H., M. Aumailley, G. Wick, R. Fleischmajer, and R. Timpl. 1984. Immunochemistry, genuine size and tissue localization of collagen VI. Eur. J. Biochem. 142:493-502.

30. Carter, W. G. 1982. The cooperative role of the transformation-sensitive glycoproteins GP140 and fibronectin in cell attachment and spreading. J. Biol. Chem. 257:3249-3257.

31. Gibson, M. A., and E. G. Cleary. 1982. A collagen-like glycoprotein from elastin-rich tissues. Biochem. Biophys. Res. Commun. 105:1288-1295.

32. Marton, L. S., and B. G. W. Arnason. 1982. A basement membrane-associated glycoprotein from skeletal muscle. J. Cell. Biochem. 19:363-381.

33. Trueb, B., and K. Winterhalter. 1986. Type VI collagen is composed of a 200-kD subunit and two 140-kD subunits. EMBO (Eur. Mol. Biol. Organ.) J. 5:2815-2819.

34. King, I. A., A. Tabiowo, P. R. Fryer, and F. M. Pope. 1989. A type VI collagen-related glycopeptide is the major concanavalin A-binding component in pig skin. Biochem. J. 257:79-86.

35. Colombatti, A., K. Ainger, and F. Colizzi. 1989. Type VI collagen: high yields of a molecule with multiple forms of alpha-3 chain from avian and human tissues. Matrix. 9:177-185.

36. Carter, W. G. 1984. The role of intermolecular disulfide bonding in deposition of GP 140 in the extracellular matrix. J. Cell. Biol. 99:105-114.

37. Crawford, S. W., J. A. Featherstone, K. Holbrook, S. L. Yong, and P. Bornstein. 1985. Characterization of a type VI collagen-related Mr-140,000 protein from cutis-laxa fibroblasts in culture. Biochem. J. 227:491-502.

38. Fauvel, F., M. E. Grant, Y. J. Legrand, H. Couchon, G. Tobelem, D. S. Jackson, and J. P. Caen. 1983. Interaction of blood platelets with a microfibrillar extract from adult bovine aorta: requirement for von Willebrand factor. Proc. Natl. Acad. Sci. USA. 80:551-554.

39. Perret, B. A., M. Furlan, P. Jeno, and E. A. Beck. 1986. von Willebrand factor-dependent agglutination of washed fixed human platelets by insoluble collagen isolated from bovine aorta. J. Lab. Clin. Med. 107:244-252.
40. Carter, W. G. 1982. Transformation-dependent alterations in glycoproteins of extracellular matrix of human fibroblasts. Characterization of GP250 and the collagen-like GP140. J. Biol. Chem. 257:13805-13915.

41. Timpl, R., and J. Engel. 1987. Type VI collagen. In Structure and Function of Collagen Types. R. Mayne and R. B. Burgeson, editors. Academic Press, Inc., Orlando, FL. 105-143.

42. Chung, E., R. K. Rhodes, and E. J. Miller. 1976. Isolation of three collagenous components of probable basement membrane origin from several tissues. Biochem. Biophys. Res. Commun. 71:1167-1174.

43. Furthmayr, H., H. Wiedemann, R. Timpl, E. Odermatt, and J. Engel. 1983. Electron-microscopical approach to a structural model of intimal collagen. Biochem. J. 211:303-311.

44. Pareti, F. I., K. Niyya, J. M. McPherson, and Z. M. Ruggeri. 1986. Isolation and characterization of two domains of human von Willebrand factor that interact with fibrillar collagen types I and III. J. Biol. Chem. 262:13835-13841.

45. Mohri, H. A. Yoshioka, T. S. Zimmerman, and Z M. Ruggeri. 1989. Isolation of the von Willebrand factor domain interacting with platelet glycoprotein $\mathrm{Ib}$, heparin, and collagen and characterization of its three distinct functional sites. J. Biol. Chem. 264:17361-17367.

46. Girma, J. P., D. Meyer, C. L. Verweij, H. Pannekoek, and J. J. Sixma. 1987. Structure-function relationship of human von Willebrand factor. Blood. 70:605-611.

47. Mohri, H., Y. Fujimura, M. Shima, A. Yoshioka, R. A. Houghten, Z. M. Ruggeri, and T. S. Zimmerman. 1988. Structure of von Willebrand Factor domain interacting with glycoprotein Ib. J. Biol. Chem. 263:17901-17904.

48. Pietu, G., P. Meullen, G. Cherel, J. Diaz, D. Baruch, M. Courtney, and D. Meyer. 1989. Production in Escherichia coli of a biologically active subfragment of von Willebrand factor corresponding to the platelet glycoprotein Ib, collagen and heparin binding domains. Biochem. Biophys. Res. Commun. 164:13391347.

49. Koller, E., K. H. Winterhalter, and B. Trueb. 1989. The globular domains of type VI collagen are related to the collagen-binding domains of cartilage matrix protein and von Willebrand factor. EMBO (Eur. Mol. Biol. Organ.) J. 8:10731077.

50. Bonaldo, P., V. Russo, F. Bucciotti, G. M. Bressan, and A. Colombatti. 1989. Alpha-1 chain of chick type VI collagen. The complete cDNA sequence reveals a hybrid molecule made of one short collagen and three von Willebrand factor type A-like domains. J. Biol. Chem. 264:5575-5580.

51. Chu, M.-L., T. C. Pan, D. Conway, H. J. Kuo, R. W. Glanville, R. Timpl, K. Mann, and R. Deutzmann. 1989. Sequence analysis of alpha $1(\mathrm{VI})$ and alpha 2(VI) chains of human type VI collagen reveals internal triplication of globular domains similar to the A domains of von Willebrand factor and two alpha 2(VI) chain variants that differ in the carboxy terminus. EMBO (Eur. Mol. Biol. Or gan.) J. 8:1939-1946.

52. Bonaldo, P., and A. Colombatti. 1989. The carboxyl terminus of the chicken alpha-3 chain of collagen VI is a unique mosaic structure with glycoprotein Ib-like, fibronectin type III, and Kunitz modules. J. Biol. Chem. 264:2023520239. 